\title{
EFFECT OF IRON ON THE BIOSYNTHESIS OF HEPATIC APOFERRITIN ${ }^{1}$
}

\author{
By SAUL R. KOREY AND BENNETT LEVINE \\ (From the Department of Medicine, Division of Neurology, the School of Medicine, Western \\ Reserve University, and University Hospitals, Cleveland, $O$.
}

(Submitted for publication December 6, 1954; accepted January 19, 1955)

Apoferritin is the protein which may play a part in the transport system for iron in the gastrointestinal cells and which serves as the main reservoir of storage iron in the liver and spleen. In combination with iron it is called ferritin. The oral administration of iron to an animal has been shown to stimulate the formation of apoferritin in the mucosa of the gastrointestinal tract. Granick (1) reported that there is a marked increase in the amount of crystallizable apoferritin chiefly in the mucosa of the upper intestinal tract of guinea pigs fed iron. Gabrio and Salomon (2) demonstrated that considerably more ferritin could be isolated from the intestinal mucosa and adjacent lymph nodes of a horse fed iron in comparison with an untreated control. Since the precipitin method of isolation employed by the latter investigators does not distinguish between apoferritin and ferritin, it is assumed that the total amount of iron storage protein was increased following the priming of animals with iron.

The present study indicates that while the in vivo incorporation of glycine labelled with $\mathrm{C}^{14}$ into ferritin (apoferritin plus ferritin) is increased by oral administration of iron, intraperitoneal injection of iron is considerably more effective in promoting this incorporation, presumably because the iron has direct access to the hepatic cells concerned with synthesis of this protein. Ferritin isolated from the mucosa of the gastrointestinal tract and from the liver of resting animals appears to be in the dynamic state. Attempts at in vitro incorporation of labelled glycine into liver ferritin have been successful, and an opportunity is afforded for the study of factors influencing biosynthesis of ferritin.

While these investigations were in progress (3), Fineberg and Greenberg (4) reported results of in vivo experiments which are similar to ours

1 This study was made possible by a generous grant from the Louis D. Beaumont Foundation. and Loftfield (5) likewise found under somewhat different experimental conditions that in vitro isotope incorporation into liver ferritin is readily achieved.

\section{METHODS AND PROTOCOLS}

Ferritin was isolated from guinea pig liver and intestine by the procedure of Laufberger (6) and Granick (7) and crystallized as its cadmium complex. Despite the heat stability of ferritin, it is useful from the standpoint of yield and crystallization to conduct the procedure of isolation from acidification onwards at 0 to $8^{\circ} \mathrm{C}$. The isolated ferritin was crystallized three times from 2 per cent ammonium sulfate unless otherwise stated. The final product dissolved in water was dialyzed against large volumes of water which was changed several times. An aliquot of the clear brown solution then was evaporated to dryness on a glass planchette. The sample was plated within range of 0.25 to $2.50 \mathrm{mgm}$. of ferritin per $\mathrm{cm}^{2}$. Estimation of $\mathrm{C}^{14}$ radioactivity was done in a standard end window counter. The minimum count was five times background, 'except in zero time experiments. Following the counting, the planchette containing the dried sample was transferred to a large test tube and digested for Kjeldahl nitrogen determination.

Ferritin crystallized three times was recovered from the in vivo experiments and run overnight in paper electrophoresis using Whatman No. 3 MM paper (8). In phosphate buffer $\mathrm{pH} 7.4, \mathrm{u}=0.06$ at $300 \mathrm{~V}$., 3.0 milliamps., paper width $14 \mathrm{~cm}$., the experimentally isolated ferritin migrated as a discrete zone which coincided with a highly purified sample of guinea pig ferritin. There was no evidence of contaminating proteins on the bromthymol blue stained paper. Although several buffers and pH's were employed both in the electrophoresis and in the elution, quantitative elution of the unstained migrated ferritin was not obtained.

\section{Protocols of in vivo studies}

Twelve guinea pigs weighing 300 to $350 \mathrm{gm}$. were paired into experimental and control groups. At the initiation of the experiment the former received $10 \mathrm{mgm}$. of ferrous iron through intraesophageal catheter while both groups were injected intraperitoneally with $\mathrm{C}^{14}$ methylene labelled glycine specific activity (cpm per mgm.) $8.4 \times$ $10^{4}$. In these and subsequent experiments the animals received $1 \times 10^{8} \mathrm{cpm}$ of isotopic glycine per $100 \mathrm{gm}$. of weight. Three pairs were sacrificed at 4 and again at 16 
hours after the start of the experiment. The livers were pooled appropriately for isolation of ferritin. An additional three guinea pigs of similar weight were injected intraperitoneally at the start of the experiment with 1.2 mgm. of ferric iron (9) as well as with the glycine. At the end of the four-hour period the livers were pooled for ferritin isolation.

Four guinea pigs weighing 400 to $500 \mathrm{gm}$. were bled by intracardiac puncture four to five times over a twoweek period. Their hemoglobin concentrations were reduced to 50 per cent of initial values. Four other animals weighing 300 to $350 \mathrm{gm}$. served as unbled controls. At the start of the experiment two bled and two control animals received orally $10 \mathrm{mgm}$. of ferrous iron. All eight guinea pigs were injected intraperitoneally with $\mathrm{C}^{\mathbf{1 4}}$ carboxyl labelled glycine S.A. $2.2 \times 10^{5}$. All the animals were sacrificed after seven hours and liver ferritin isolated.

The intestinal tracts of the 20 animals used in the first two experiments were pooled on the basis of whether or not they received iron orally. Those to whom iron was given intraperitoneally were excluded. At the ammonium sulfate fractionation step of ferritin isolation, $2.74 \mathrm{mgm}$. of highly purified guinea pig ferritin were added to each sample. The ferritin finally isolated was crystallized twice prior to counting.

\section{Protocols on in vitro studies}

Animals primed with $3.2 \mathrm{mgm}$. ferric iron administered intraperitoneally were sacrificed twenty minutes after the injection and their livers removed, weighed and minced. The livers were homogenized for 15 seconds

TABLE I

Stimulation of hepatic synthesis of apoferritin by iron *

\begin{tabular}{|c|c|c|c|}
\hline Time/hrs. & Iron & $\begin{array}{l}\text { cpm/mgm. } \\
\text { ferritin nitrogen }\end{array}$ & $\begin{array}{l}\text { Relative incorporotion } \\
\text { C }^{\text {is }} \text { into liver ferritin }\end{array}$ \\
\hline \multirow{3}{*}{4} & 0 & 460 & 1.0 \\
\cline { 2 - 4 } & $10 \mathrm{mg}$ p.o. & 1100 & 2.4 \\
\cline { 2 - 4 } & $1.2 \mathrm{mg}$ i.p. & 5300 & 11.5 \\
\hline \multirow{2}{*}{16} & 0 & 335 & 1.0 \\
\cline { 2 - 4 } & $10 \mathrm{mg} \mathrm{po}$ & 1120 & 3.3 \\
\hline
\end{tabular}

* $\mathrm{C}^{14}$ methylene labelled glycine (S.A. $8.4 \times 10^{4}$ ) was injected intraperitoneally into all animals at the start of the experiment. One million cpm (counts per minute) were given for each 100 grams animal weight. Iron was administered as indicated: controls received no iron; the experimental animals received either $10 \mathrm{mgm}$. ferrous iron as ferrous sulfate by mouth (p.o.), or $1.2 \mathrm{mgm}$. ferric iron as ferric ammonium citrate intraperitoneally (i.p.). Three animals were used for each point, their livers being pooled. The experiments were terminated at 4 and 16 hours, respectively. In column IV, the extent of incorporation of $\mathrm{C}^{14}$ isotope derived from glycine is seen to be doubled or tripled by administration of oral iron and increased eleven-fold by intraperitoneal iron.
TABLE II

The effect on apoferritin formation of oral administration of iron to anemic animals*

\begin{tabular}{|c|c|c|c|c|}
\hline Group & Bled & tron & $\begin{array}{l}\text { cpm/mgm. } \\
\text { ferritin nitrogen }\end{array}$ & $\begin{array}{l}\text { Relative incorporation } \\
\mathrm{C}^{\text {s4 }} \text { into ilver ferritin }\end{array}$ \\
\hline A & + & - & 392 & \multirow{2}{*}{$B / A=3.6$} \\
\hline B & + & 10mppo & 1400 & \\
\hline C & - & - & 945 & \multirow{2}{*}{$0 / c=2.7$} \\
\hline D & - & $10 \mathrm{mg} \mathrm{pol}$ & 2520 & \\
\hline
\end{tabular}

${ }^{*} \mathrm{C}^{14}$ carboxyl labelled glycine (S.A. $2.2 \times 10^{5}$ ) was injected intraperitoneally at the start of the experiment. Each animal received $1 \times 10^{\circ} \mathrm{cpm}$ per 100 grams of body weight. Those of groups $B$ and $D$ also received $10 \mathrm{mgm}$. ferrous iron as ferrous sulfate by mouth. Duration of the experiment was 7 hours. For two weeks before the experiment, the animals of groups $A$ and $B$ had been bled to about half normal hemoglobin concentration. In column $\mathrm{V}$ the ratios demonstrate the effect of oral iron on the synthesis of hepatic ferritin. They suggest a slight acceleration of ferritin synthesis in response to oral iron associated with relative iron deficient state of the animals, but again demonstrate in both series the effect of oral iron in increasing isotopic incorporation into hepatic ferritin in comparison with untreated animals.

in twice the volume of buffer containing nicotinamide $0.025 \mathrm{M}, \mathrm{MgCl}_{2} 0.007 \mathrm{M}$, sucrose $0.126 \mathrm{M}, \mathrm{K}_{2} \mathrm{HPO}_{4} 0.04$

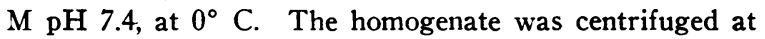
$500 \mathrm{~g}$ for 10 minutes $(10,11)$. The cell free supernatant was added to the incubation medium which was agitated gently for one hour at $37^{\circ} \mathrm{C}$. under anaerobic conditions. The incubation media differed in the addition or omission of creatine phosphate and phosphoglycerate. At the end of the experiment ferritin was isolated in the usual manner. Fourteen and a half milligrams of highly purified horse ferritin were added as carrier at the ammonium sulfate state so that the final product could be recrystallized several times and the per cent recovery determined.

In several experiments ferric iron was added directly to the homogenate or to liver slices and the incubation carried out aerobically as well as anaerobically.

\section{RESULTS}

The oral administration of $10 \mathrm{mgm}$. ferrous iron to normal guinea pigs stimulates the incorporation into liver ferritin of $\mathrm{C}^{14}$ derived from either methylene or carboxyl labelled glycine. The amount of isotope incorporation is two and one-half to three and one-half times that found in unfed controls. When $1.2 \mathrm{mgm}$. of ferric iron is injected intraperitoneally the isotope concentration in liver ferritin is 10 to 12 times that in untreated controls 
(Tables I and II). This represents the formation of about 30 per cent new protein based on the molar ratio of glycine to protein of $200 / 1$ (12).

Relatively acute bleeding of the animals does not greatly increase the ability of orally fed iron to stimulate ferritin synthesis. In column 5 , Table II, the ratios indicate the possibility that more iron reaches the hepatic cells in the anemic animals than in the normal animals, and is thus responsible for increasing the proportion of isotope incorporation between iron fed and untreated groups.

The extent of incorporation of labelled amino acid into intestinal ferritin appeared quite similar whether or not iron had been administered orally. In the unfed group there were $272 \mathrm{cpm}$ per mgm. nitrogen intestinal ferritin as compared to $330 \mathrm{cpm}$ per mgm. intestinal ferritin. When this was corrected for recovery of the added carrier, the ratio approached 1.0. The specific activity of the intestinal ferritin was considerably higher than indicated because of the dilution by carrier.

Protein precipitates derived from the early stages of the isolation procedure for ferritin did not show any consistent difference in specific activity which could be related to the effect of iron feeding on their synthetic rates.

In a series of experiments performed in the manner described for the study of the effects of intraperitoneal administration of iron, the cupric and manganous forms of these metals were administered simultaneously with iron. No influence on isotope incorporation into liver ferritin was demonstrated beyond a moderate depression of incorporation with $2 \mathrm{mgm}$. of intraperitoneally injected copper.

Experiments done with the usual tissue slice techniques and by brief homogenization of the liver were not successful unless the animals were injected with iron prior to the removal of the liver. Addition of ferric iron in Belloni's solution (8) to well buffered tissue systems did not induce sufficient incorporation of labelled glycine to conduct comparative experiments. However, by intraperitoneal injection of ferric iron $20 \mathrm{~min}$ utes before sacrificing the animal, significant amounts of isotope from carboxyl labelled glycine were incorporated into liver ferritin during incubation of the homogenized liver (Table III).

These experiments likewise demonstrated that the addition of creatine phosphate and phospho-
TABLE III

In vitro incorporation of labelled ylycine into hepatic apoferritin *

\begin{tabular}{|c|c|c|c|}
\hline Exp. & Iron & $\begin{array}{c}\text { C.P. } \\
\text { P.G. }\end{array}$ & $\begin{array}{c}\text { cpm/ mgm. ferritin } \\
\text { nitrogen }\end{array}$ \\
\hline 1 & + & + & 150. \\
\hline 2 & + & - & 64. \\
\hline 3 & - & - & 14.5 \\
\hline
\end{tabular}

* Each incubation vessel contained a cell free liver extract equivalent to 16.0 grams of liver suspended in buffered sucrose. Two hundred thousand cpm of $\mathrm{C}^{\mathbf{1 4}}$ carboxyl labelled glycine (S.A. $2.07 \times 10^{5}$ ) were added per cc. of incubation medium. Animals whose livers were used for experiments 1 and 2 received intraperitoneally $3.2 \mathrm{mgm}$. ferric iron as ferric ammonium citrate $20 \mathrm{~min}$ utes before being sacrificed. In experiment 1 , creatine phosphate (C.P.) and phosphoglycerate (P.G.) were added to final concentration of 20 and $10 \mu \mathrm{M}$ per cc., respectively. Incubation was for one hour under $\mathrm{N}_{2}$. Experiment 3 is a control. At the termination of the experiments the native ferritin was isolated with the addition of $14.5 \mathrm{mgm}$. carrier ferritin. The results in column IV are not corrected for dilution, which would be a factor of about 10. A significant incorporation of amino acid is noted in experiments 1 and 2 . The effect of added high energy phosphate compounds in doubling the extent of incorporation of isotopic glycine into liver ferritin under anaerobic conditions is likewise evident.

glycerate to the incubation medium augments the isotopic incorporation into liver ferritin two or three times that obtained in their absence.

\section{DISCUSSION}

The accumulated evidence of experimental work $(1,2,4,5)$ supports the original concept of Granick (7) and Michaelis (13) that the appearance of iron in the environment of the cellular system capable of synthesizing apoferritin induces a de nowo formation of this protein. Aside from the qualitative studies of Braunsteiner, Gisinger, and Pakesch (14) prior work has been confined to the study of ferritin synthesis in the gastrointestinal mucosa. However the experiments presented here have extended the applicability of this concept to include the de novo synthesis of liver ferritin in vivo and perhaps in vitro. The limited effectiveness of relatively large doses of oral iron in stimulating hepatic ferritin synthesis doubtless depends on the small amount of iron normally transported across the intestinal mucosa and into 
the circulation. Nevertheless, it is apparent that sufficient iron reaches the liver to double or triple the resting incorporation rate (15). The elevenfold increase in incorporation of isotope into liver ferritin when iron is administered intraperitoneally demonstrates the effect of iron in initiating the formation of apoferritin when it is able to reach the hepatic cells in sufficient amounts. It would be of interest to estimate the capacity of the hepatic system for unrestricted synthesis of ferritin since in addition to serving as iron storage protein, it might be a potential detoxifying mechanism for excess iron which is known to be harmful. The extent and the rapidity of the response of the synthesizing system to the specific stimulus of iron is such that in four hours an amount equivalent to one-third of the apoferritin in the unstimulated liver is made. The data suggest that despite the fact that ferritin is a storage protein it appears to share the dynamic state common to other metabolites if one may assume that incorporation of amino acid into apoferritin of liver and intestine in untreated animals reflects a continual turnover of ferritin.

The apparent absence of an iron effect on synthesis of intestinal ferritin probably is the result of the technical problem of the minute amounts of this protein that can be isolated. The proportion of native to carrier apoferritin must be very high and yet for purification necessarily so. The observations of Gabrio and Salomon (2) are more pertinent with respect to intestinal synthesis of apoferritin.

The minor effect of relatively acute bleeding in promoting significantly increased isotopic incorporation into liver ferritin must be viewed in light of the results of Hahn, Bale, Ross, Balfour, and Whipple (15), whose data show a nine-fold increase in iron absorption under similar conditions. The absorbed iron preferentially is utilized for heme synthesis and implies a mechanism whereby iron is successfully trapped within the bone marrow rather than in the hepatic cells concerned with ferritin formation.

From the experimental data of Table III it is possible to estimate the amount of incorporation of amino acid or apoferritin formed in vitro as well as the per cent of total apoferritin this represents. Many experiments have shown that about
$1.5 \mathrm{mgm}$. of apoferritin can be isolated from 15.0 grams of guinea pig liver previously stimulated by iron. The addition of $14.5 \mathrm{mgm}$. of carrier apoferritin thus represents a dilution of five to ten times the native protein. The specific activity of the isolated samples is $150 \mathrm{cpm}$ per mgm. N, which when corrected for dilution amounts to 750 to $1500 \mathrm{cpm}$ per mgm. N. On this basis, the extent of incorporation of labelled glycine or alternatively the de novo synthesis of apoferritin is 1.8 to 3.6 per cent of the native protein. The per cent recovery after recrystallizations as determined by recovery of the carrier is 50 per cent. The total incorporation of $\mathrm{C}^{14}$ derived from glycine, and assumed to enter the protein as glycine, is $350 \mathrm{cpm}$ equivalent to the possible formation of $1 \times 10^{-4}$ $\mu \mathrm{M}$ of new apoferritin. Since $1 \times 10^{-4} \mu \mathrm{M}$ of apoferritin represents 1.8 to 3.6 per cent of all apoferritin, the total iron storage protein in 16 grams of liver stimulated by iron would be 1.5 to $3.0 \mathrm{mgm}$. This is sufficient to combine with 0.3 to $1.0 \mathrm{mgm}$. of iron, or at best, one-third that injected 20 minutes before sacrificing the animal.

An effect of high energy phosphate donors in these experiments is to increase the extent of incorporation two to three-fold when compared to the unfortified homogenate, which contains these compounds although in lesser amounts. Our failure to obtain adequate synthesis when iron was added directly to the homogenate should be mentioned, since it would be useful to incorporate both iron and an amino acid simultaneously into ferritin in vitro.

\section{SUM M ARY}

1. The administration of oral iron to normal guinea pigs increases the incorporation of $\mathrm{C}^{14} \mathrm{de}$ rived from methylene or carboxyl labelled glycine in liver ferritin when compared with unfed controls.

2. Intraperitoneally injected iron increased the rate of incorporation 10 times over control values.

3 . An in vitro system for apoferritin synthesis is described.

4. The percentage of new apoferritin arising in vivo from iron stimulation of the liver is 30 per cent, whereas the in vitro incorporation of glycine amounts to 3 per cent of the native apoferritin. 


\section{REFERENCES}

1. Granick, S., Ferritin. IX. Increase of the protein apoferritin in the gastrointestinal mucosa as a direct response to iron feed. The function of ferritin in the regulation of iron absorption. J. Biol. Chem., 1946, 164, 737.

2. Gabrio, B. W., and Salomon, K., Distribution of total ferritin in intestine and mesenteric lymph nodes of horses after iron feeding. Proc. Soc. Exper. Biol. \& Med., 1950, 75, 124.

3. Korey, S. R., and Levine, B., In vivo synthesis of ferritin. Federation Proc., 1954, 13, 81.

4. Fineberg, R. A., and Greenberg, D. M., Stimulation of ferritin biosynthesis by iron. Federation Proc., 1954, 13, 207.

5. Loftfield, R. B., In vivo and in vitro incorporation of C-14 leucine into ferritin. Federation Proc., 1954, 13, 465.

6. Laufberger, M. V., Sur la cristallisation de la ferritine. Bull. Soc. chim. biol., 1937, 19, 1575.

7. Granick, S., Ferritin. I. Physical and chemical properties of horse spleen ferritin. J. Biol. Chem., 1942, $146,451$.

8. Larson, D. L., and Ranney, H. M., Filter paper electrophoresis of human hemoglobin. J. Clin. Invest., 1953, 32, 1070.
9. Belloni, E., The organic salts of iron. II. Ferric citrates and ferric ammonium citrates. Gazz. chim. ital., 1920, 50, 159.

10. Bucher, N. L. R., The formation of radioactive cholesterol and fatty acids from $\mathrm{C}^{\mathbf{1}}$-labelled acetate by rat liver homogenates. J. Am. Chem. Soc., 1953, 75, 498.

11. Zamecnik, P. C., and Keller, E. B., Relation between phosphate energy donors and incorporation of labelled amino acids into proteins. J. Biol. Chem., 1954, $209,37$.

12. Mazur, A., Litt, I., and Shorr, E., Chemical properties of ferritin and their relation to its vasodepressor activity. J. Biol. Chem., 1950, 187, 473.

13. Michaelis, L., Ferritin and apoferritin. N. Y., Academic Press, Adv. Protein Chem., 1947, vol. III, 53.

14. Braunsteiner, H., Gisinger, E., and Pakesch, F., Ferritin, transferrin und serumeisen. Klin. Wchnschr., 1952, 30, 394.

15. Hahn, P. F., Bale, W. F., Ross, J. F., Balfour, W. M., and Whipple, G. H., Radioactive iron absorption by gastro-intestinal tract. Influence of anemia, anoxia, and antecedent feeding distribution in growing dogs. J. Exper. Med., 1943, 78, 169. 